\title{
Stress Concentration Studies in Flat Plates with Rectangular Cut-Outs Using Finite Element Method
}

\author{
Dheeraj Gunwant \\ GET Group of Institutions \\ Faculty of Technology, Bazpur, Uttarakhand, India \\ E-mail: mailto.dheerajgunwant@gmail.com \\ (Received May 28, 2018; Accepted August 6, 2018)
}

\begin{abstract}
Presence of cut-outs of different shapes is inevitable and is many times considered to be a desirable feature for the design of light-weight components. However, the presence of such cut-outs induces highly localized stresses in their vicinity which cannot be resolved using analytical relations and elementary equations of the strength of materials. In the recent years, FEM has evolved as a crucial tool for handling such problems with reduced degree of complexity. The present investigation is aimed at studying the effect of various geometrical parameters and loading scenarios on the SCF induced in an infinite plate in presence of rectangular cut-out with filleted corners. In the first step, the model was subjected to uniaxial load and the obtained values of SCF exhibited good agreement with analytical values. The model was further subjected to systematically varied stress states and geometrical parameters in order to study their effect on the SCF.
\end{abstract}

Keywords- FEM, Stress-concentration, ANSYS, SCILAB, Rectangular cut-out.

\section{Introduction}

The design of high-performance engineering components poses many challenges in front of designer such as the inclusion of holes for fastening and making the component lightweight. Many times, the product has irregular boundaries and contours leading to concentration of stress at different locations. The inclusion of a defect also leads to elevated stresses around them leading to premature failure of components (Spotts, 1971). The devastating effects of stress-raisers are automatically suppressed in case of ductile materials due to plastic flow around them. However, brittle materials exhibit sudden and complete failure of components due to the absence of plastic flow (Kumar et al., 2016). In order to minimize the chances of premature failure, the designer must include the presence of irregularities in components. Real life structures have discontinuities of various forms such as doors and windows in the body of aircraft and submarines, mountings on boilers for attaching barometers, the connection of cables and pipes and circulation of cooling fluids in turbine blades.

The determination of stress-concentrations due to these discontinuities is an imperative but challenging task for the designer (Muminovic et al., 2014). In order to study the mechanisms of fracture in isotropic plates, it becomes important to determine the stress concentration factor (SCF) in the case of stress-raisers of different shape. In this regard, the earliest of attempts were made by Savin (1961) and Lekhnitskii (1968) by providing classical analytical solutions for stress-concentration problems. Analytical solutions for SCF in isotropic structural elements containing differently shaped cut-outs have been presented by Muskhelishvili (2013). Since then Many important studies have been conducted through the use of photo elasticity by Dally and Riley (1965), finite element method FEM by Sloan et al. (1999), Garrell et al. (2003), Louhghalam et al. (2011). Since then, many researchers have tried to determine SCF in isotropic 
International Journal of Mathematical, Engineering and Management Sciences

Vol. 4, No. 1, 66-76, 2019

https://dx.doi.org/10.33889/IJMEMS.2019.4.1-006

and orthotropic plates weakened with holes having a variety of geometric shapes such as circular (Sharma, 2011), elliptical (Khechai et al., 2018), square and rectangular (Ukadgaonker et al., 2000). FEM has gained popularity over experimental methods such as photo elasticity due to its acceptability and availability of various commercial softwares. Most of the researchers have studied stress distribution around circular and elliptical shaped cut-outs due to the reason that they are the most preferable shapes for actual components. The notable contribution has been made by Rezaeepazhand and Jafari (2010) by studying the SCFs in flat plates weakened by a variety of cut-out shapes. Wu and Mu (2003) studied the SCF in flat plates and cylinders with circular holes. On the other hand, less attention has been paid to rectangular cut-outs owing to stress singularities at corners, limiting their practicality (Khechai et al., 2018). A flexible method has been devised by Su et al. (2018) to determine the stresses present at the edge of varying geometry holes (circle, triangle and square) in anisotropic plates. The method was validated through finite element simulation and displayed good agreement. Functionally graded plates containing rectangular holes were analyzed by Dave and Sharma (2018) using the method of complex variables. Effect of various parameters such as Young's modulus, Poisson's ratio, variation in material properties, the shape of the hole and applied loading on the material orientation have been studied by them.

The present investigation is concerned with studying the effect of various factors on SCF in case of a thin flat plate weakened by a central rectangular hole with filleted corners under uniaxial as well as biaxial loading. Such problems can be considered a simplified representation of rectangular windows in the fuselage of airplanes. Commercially available FE solver ANSYS was employed for the modeling, meshing and analysis of the plate consisting of rectangular holes. FE results for plates subjected to uniaxial loading with filleted holes were validated by analytical equations from literature for SCF and a good agreement was observed between them. The FE method was further employed to study the effect of fillet radius, the aspect ratio of the rectangular cut-out and the loading scenario $\left(\sigma_{2} / \sigma_{1}\right)$ on SCF in plates subjected to biaxial loading.

\section{Description of the Problem}

The problem considered in the present investigation is a thin, isotropic square flat plate of dimensions $1000 \times 1000 \times 10 \mathrm{~mm}^{3}$ consisting of a centrally located rectangular cut-out of dimensions $2 \mathrm{~b} \times 2 \mathrm{a} \mathrm{mm^{2 }}$ with filleted corners of radius ' $r$ '. Owing to the symmetry, only onequarter has been considered for FE modeling in ANSYS WB v12. The plate meshed with 3D solid brick elements. In order to account for the high stress-gradient near the hole and develop mesh independence, the mesh was refined through adaptive meshing technique until the difference in calculated stresses between two successive iterations was less than or equal to $3 \%$. The plate was subjected to a uniform loading of $1 \mathrm{MPa}$ in case of both uniaxial and biaxial loadings until and unless stated. The geometry of plate and boundary conditions are shown in Figure 1. 
International Journal of Mathematical, Engineering and Management Sciences

Vol. 4, No. 1, 66-76, 2019

https://dx.doi.org/10.33889/IJMEMS.2019.4.1-006

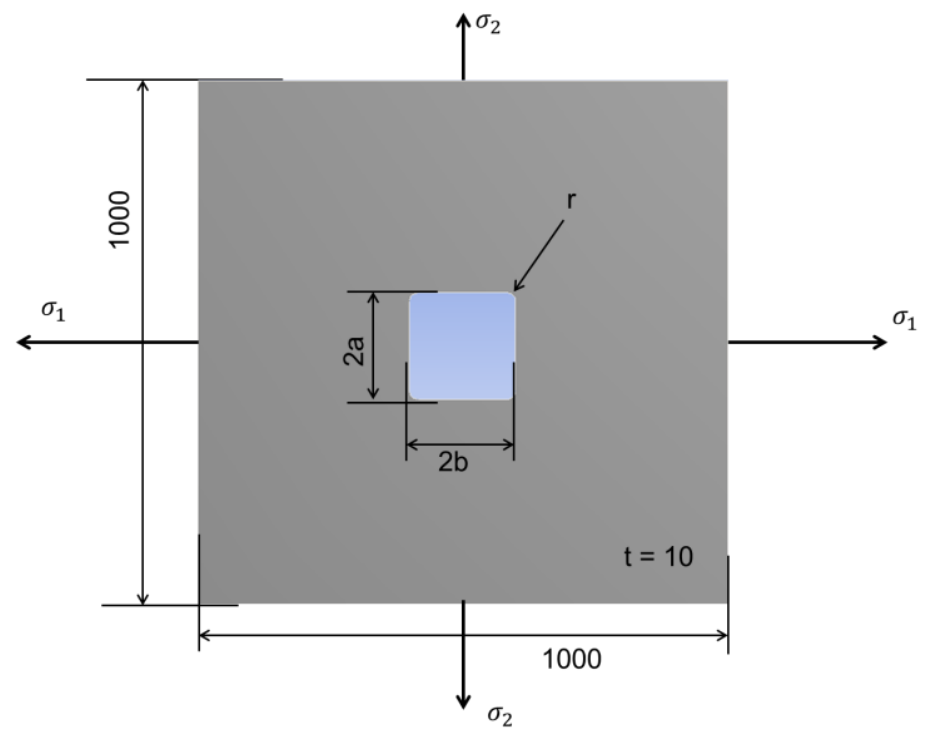

Figure 1. Geometry of plate and boundary conditions

The plate was considered to possess Young's modulus equal to $200 \times 10^{5} \mathrm{MPa}$ and Poisson's ratio equal to 0.33 . Solid 186 element was employed for the discretization of the FE model. The element is three-dimensional and consists of 20 nodes having three degrees of freedom namely translations in $\mathrm{x}, \mathrm{y}$ and $\mathrm{z}$ directions per node. Material behaviour such as plasticity, creep, stress stiffening, large deflection and strain are supported by solid186 element. Figure 2 shows the geometry options and location of nodes for solid 186.
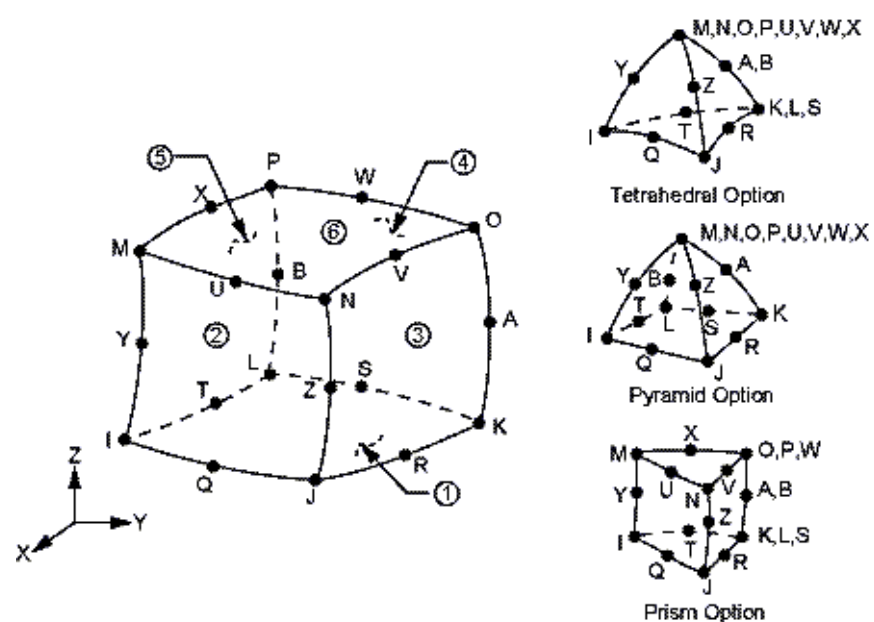

Figure 2. Geometry options and location of nodes for solid186 element 
International Journal of Mathematical, Engineering and Management Sciences

Vol. 4, No. 1, 66-76, 2019

https://dx.doi.org/10.33889/IJMEMS.2019.4.1-006

The convergence behaviour of the FE model $(\mathrm{r} / \mathrm{a}=0.05)$ for a convergence criterion of $3 \%$ under biaxial and uniaxial loading are shown in Figure 3. The FE model exhibited smooth convergence characteristics under biaxial loading and converged after five solutions as shown in Figure 3 (a) (b). Under uniaxial loading, the X-direction stress exhibited non-uniform convergence behaviour. On the other hand, the Y-direction stress displayed a uniform and smooth convergence curve. The adaptive convergence, due to minimal user intervention is better than manual one as ANSYS automatically determines the optimal mesh size near cut-outs. The solution is automatically stopped as soon as the user defined criterion is met with.

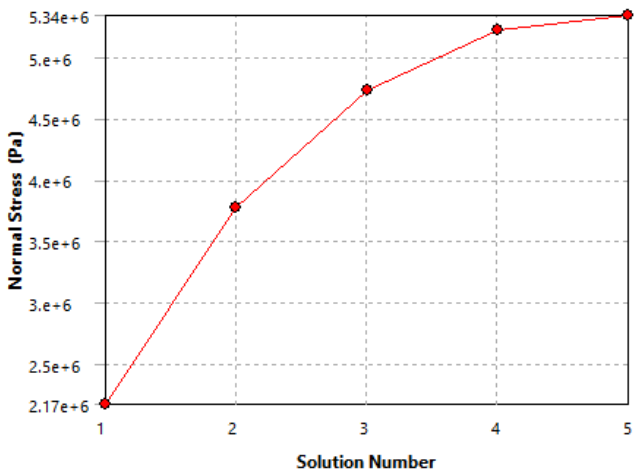

(a)

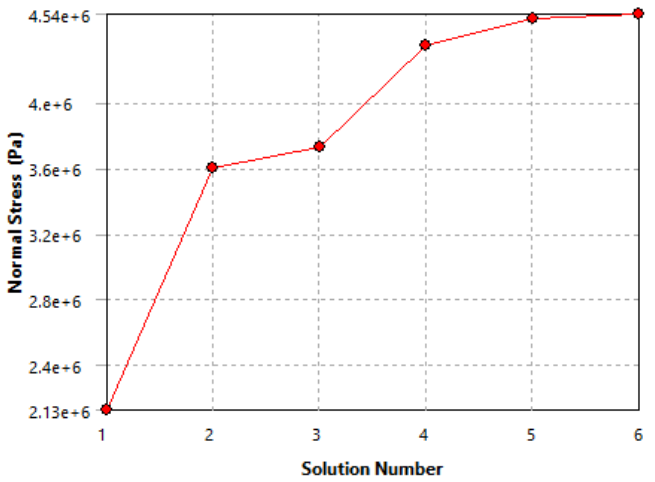

(c)

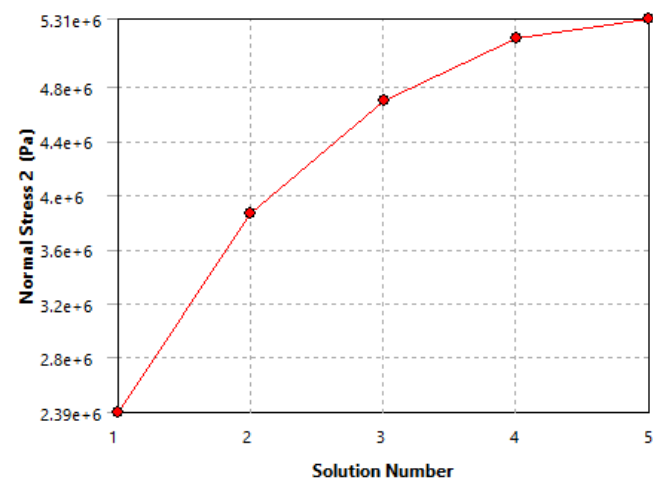

(b)

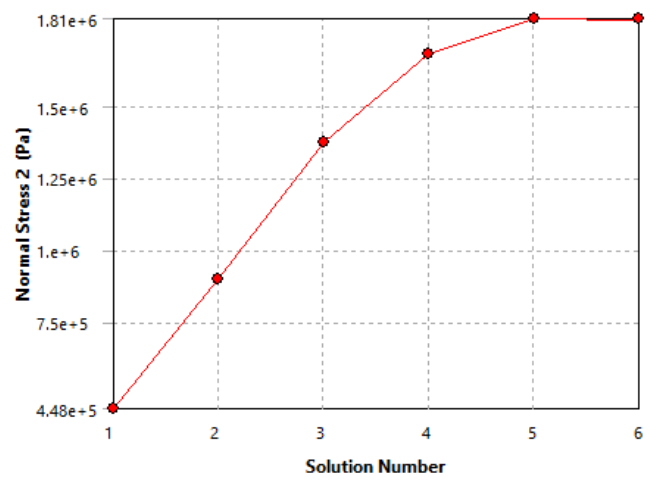

(d)

Figure 3. Convergence behaviour of the FE model for $\mathrm{r} / \mathrm{a}=0.05$ under (a) - (b) biaxial loading and (c) $-(\mathrm{d})$ uniaxial loading

\section{Analytical Relations}

In order to validate the results of FEA, the results were compared to the analytical relations from Young and Budynas (2002). SCF were calculated for varying geometry of rectangular cut-out and fillet radius. The relations are given in equation (1-5). 
International Journal of Mathematical, Engineering and Management Sciences

Vol. 4, No. 1, 66-76, 2019

https://dx.doi.org/10.33889/IJMEMS.2019.4.1-006

For $0.2 \leq r / b \leq 1.0$ and $0.3 \leq b / a \leq 1.0$

We have,

$$
\begin{aligned}
& C_{1}=14.815-15.774 \sqrt{r / b}+8.149 r / b \\
& C_{2}=-11.201-9.750 \sqrt{r / b}+9.600 r / b \\
& C_{3}=0.202+38.662 \sqrt{r / b}-27.370 r / b \\
& C_{4}=3.232-23.002 \sqrt{r / b}+15.482 r / b \\
& K_{t}=C_{1}+C_{2}(b / a)+C_{3}(b / a)^{2}+C_{4}(b / a)^{3} \\
& \sigma_{\max }=K_{t} \sigma_{1}
\end{aligned}
$$

Where, ' $r$ ', ' $b$ ' and 'a' represent the geometric parameters of the rectangular cut-out as shown in Figure 1. $\mathrm{C}_{1}, \mathrm{C}_{2}, \mathrm{C}_{3}$ and $\mathrm{C}_{4}$ are constants, $\mathrm{K}_{\mathrm{t}}$ represents the $\mathrm{SCF}$ and $\sigma_{\max }$ represents the maximum stress. In order to make the procedure computationally efficient, the analytical relations were coded in SCILAB 6.0.

\section{Results \& Discussion}

Stress concentration factors for isotropic finite plates with central rectangular cut-outs with filleted corners have been investigated. The plate is subjected to uniaxial as well as biaxial loading and effect of various factors such as fillet radius, load ratio; aspect ratio of the rectangle have been studied. The results are presented in this section.

\subsection{Validation}

Flat plate with different ' $r / b$ ' and ' $b / a$ ' values were subjected to uniaxial loading of magnitude 1 $\mathrm{MPa}$. Obtained values of maximum stress in $\mathrm{X}$ - direction were normalized w.r.t. the applied stress of $1 \mathrm{MPa}$. The values were compared with analytical equations for SCF provided in the literature. 
International Journal of Mathematical, Engineering and Management Sciences

Vol. 4, No. 1, 66-76, 2019

https://dx.doi.org/10.33889/IJMEMS.2019.4.1-006

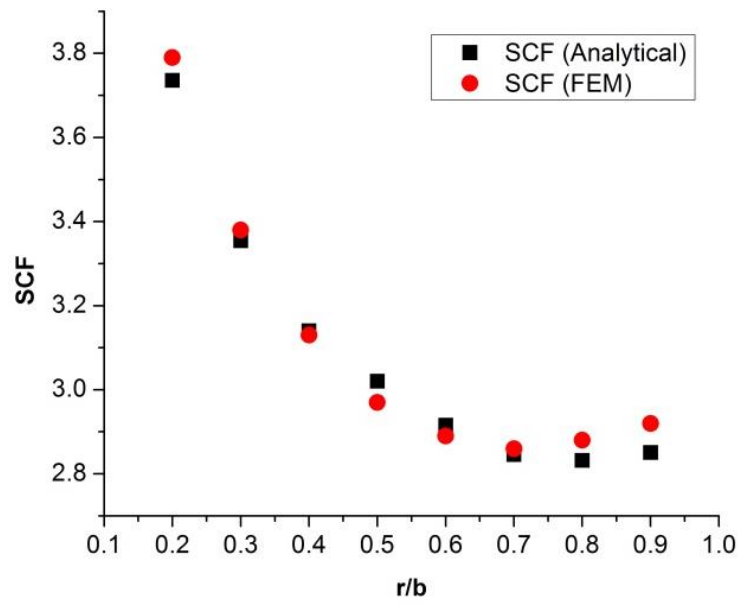

(a)

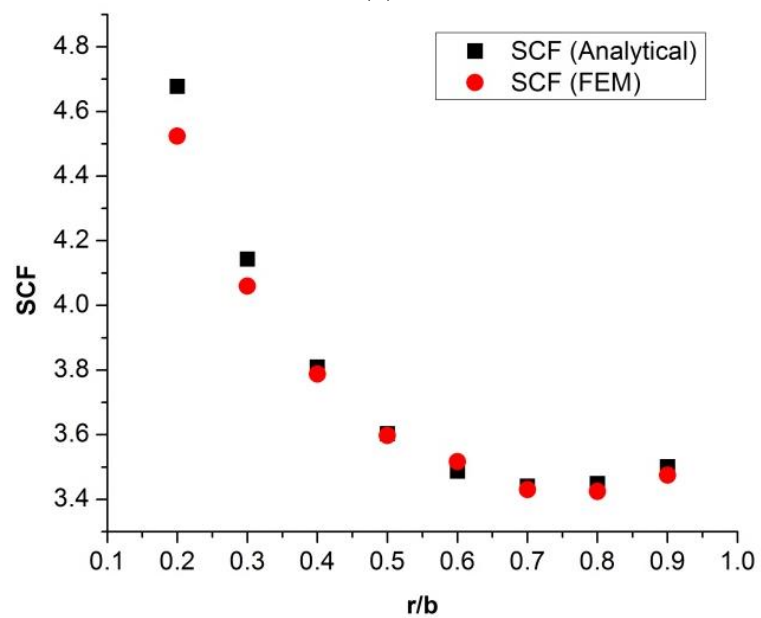

(c)

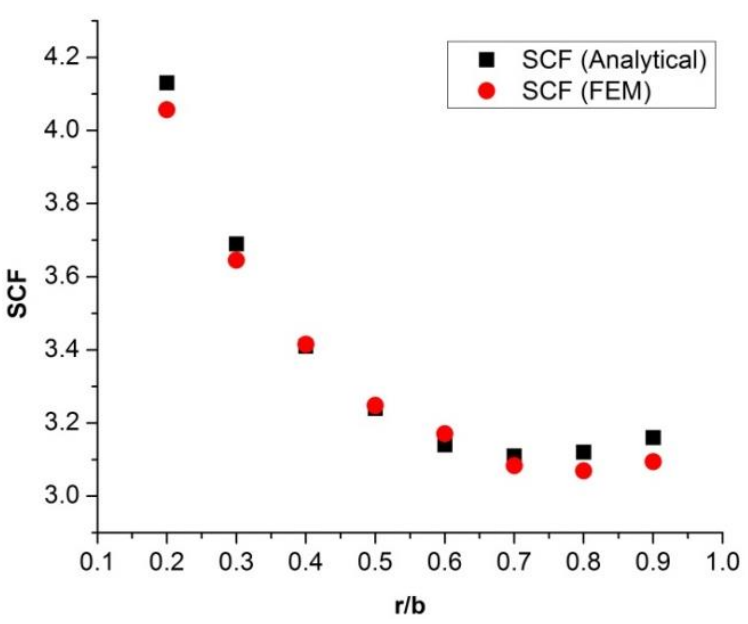

(b)

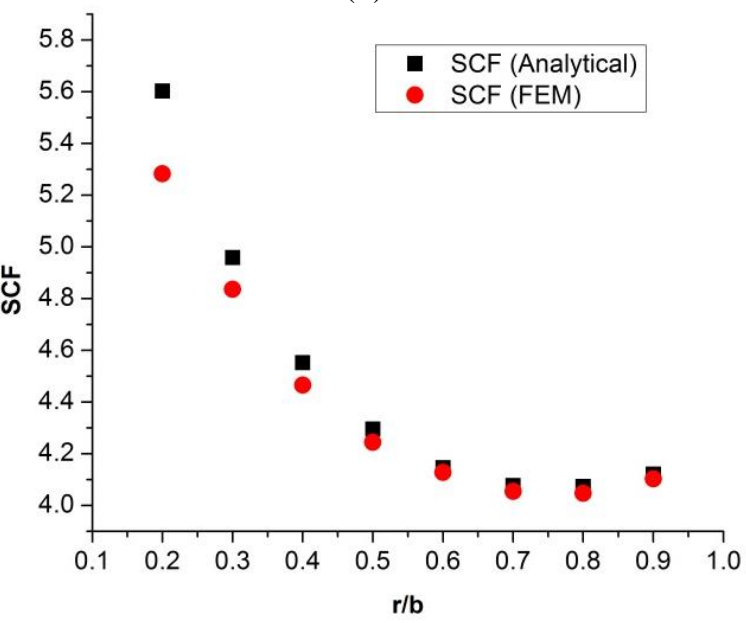

(d)

Figure 4. Variation of SCF with $r / b$ for (a) $b / a=1$, (b) $b / a=0.8$, (c) $b / a=0.6$ and (d) $b / a=0.4$

Figure 4. (a) - (d) shows the variation of SCF with $r / b$ values for different values of ' $b / a$ '. The SCF was observed to reduce with increasing $\mathrm{r} / \mathrm{b}$ ratios exhibiting the stress mitigating effect of fillet radius. Analytical as well as FEA obtained values were exhibited good agreement with each other with an increasing trend after $\mathrm{r} / \mathrm{b}=0.7$. 
International Journal of Mathematical, Engineering and Management Sciences

Vol. 4, No. 1, 66-76, 2019

https://dx.doi.org/10.33889/IJMEMS.2019.4.1-006

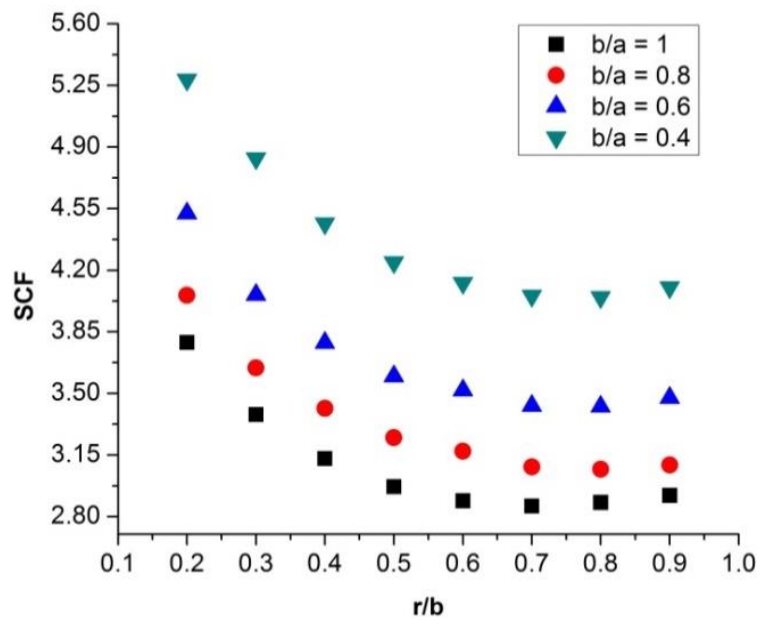

Figure 5. Relative variation of predicted values of SCF using FEM

Figure 5 shows the relative variation of SCF under uniaxial loading as determined by FEM. Highest values of SCF were obtained for ' $\mathrm{b} / \mathrm{a}$ ' value equal to 0.4. As the aspect ratio was varied to 1 , the SCF was observed to reduce significantly. For all values of ' $b / a$ ', the maximum SCF was observed for ' $\mathrm{r} / \mathrm{b}$ ' value of 0.2 i.e. when the fillet radius was smallest indicating the stress raising the effect of sharp ends.

\subsection{Effect of $r / b$ Ratio on SCF under Biaxial Loading}

Figure 6 (a) and (b) shows the effect of $\mathrm{r} / \mathrm{b}$ ratio on SCF in $\mathrm{X}$ and $\mathrm{Y}$ directions under biaxial loading.

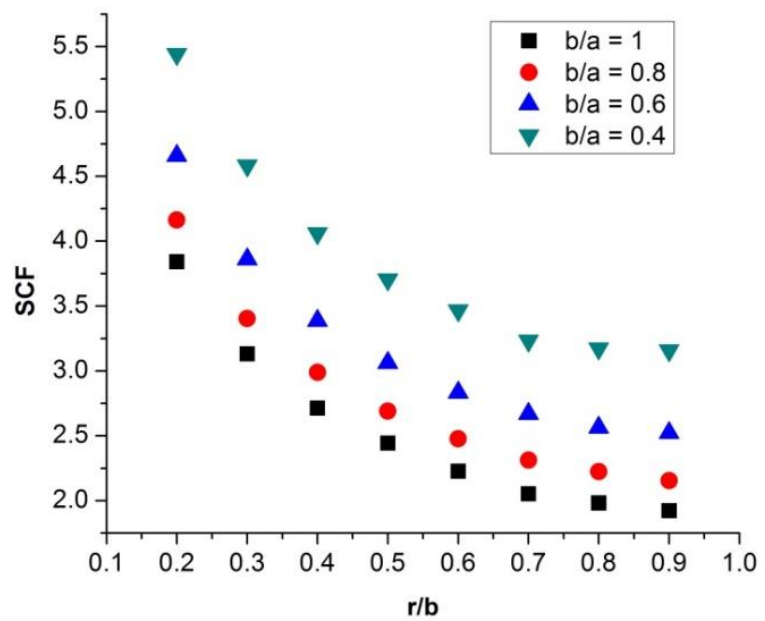

(a)

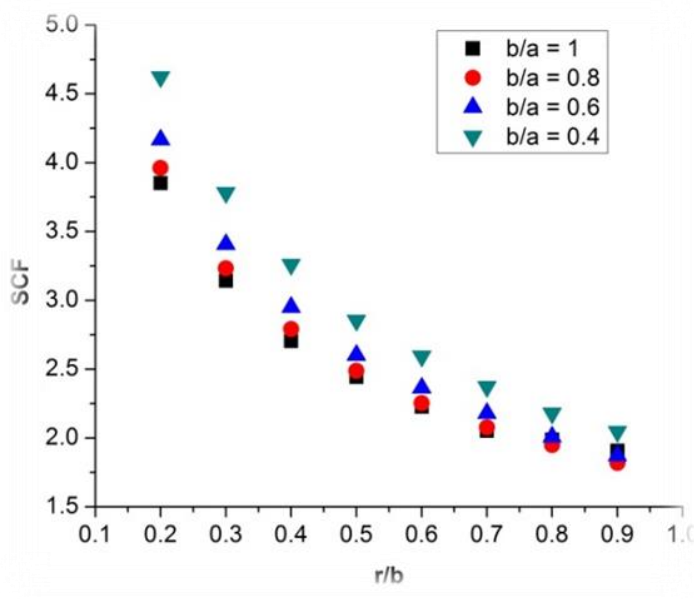

(b)

Figure 6. Variation of SCF in (a) X and (b) Y directions under biaxial loading 
International Journal of Mathematical, Engineering and Management Sciences

Vol. 4, No. 1, 66-76, 2019

https://dx.doi.org/10.33889/IJMEMS.2019.4.1-006

The maximum SCF in X-direction was observed to be $34.17 \%$ higher in case of cut-out with 'b/a' ratio of 0.4 and ' $r$ / $b$ ' ratio 0.2 w.r.t. ' $b / a$ ' ratio of 1 and same ' $r / b$ ' ratio. On the other hand, maximum SCF in Y-direction showed lower value at same values of ' $\mathrm{r} / \mathrm{b}$ ' and 'b/a'. For example, in case of ' $b / a$ ' ratio of ' 0.4 ' and ' $r / b$ ' ratio of 0.2 the SCF in Y-direction was obtained to be 4.333 which is $12.48 \%$ higher than that obtained for ' $b / a$ ' ratio of 1 and same ' $r / b$ ' ratio. It can also be observed that the SCF in both X and Y directions reduced significantly with increasing ' $\mathrm{r} / \mathrm{b}$ ' ratio.

\subsection{Effect of Loading Ratio}

In order to study the effect of the stress system on SCF, applied stresses were varied systematically to obtain various loading ratios $\left(\sigma_{2} / \sigma_{1}\right)$.

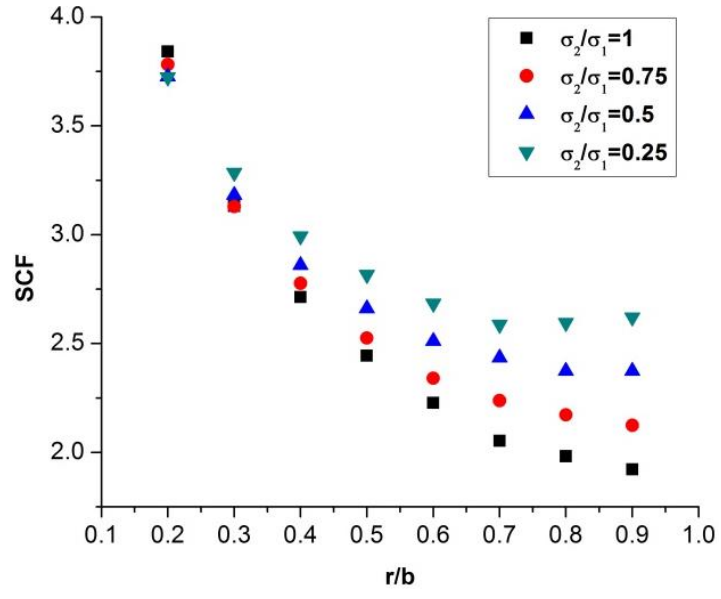

(a) X - direction

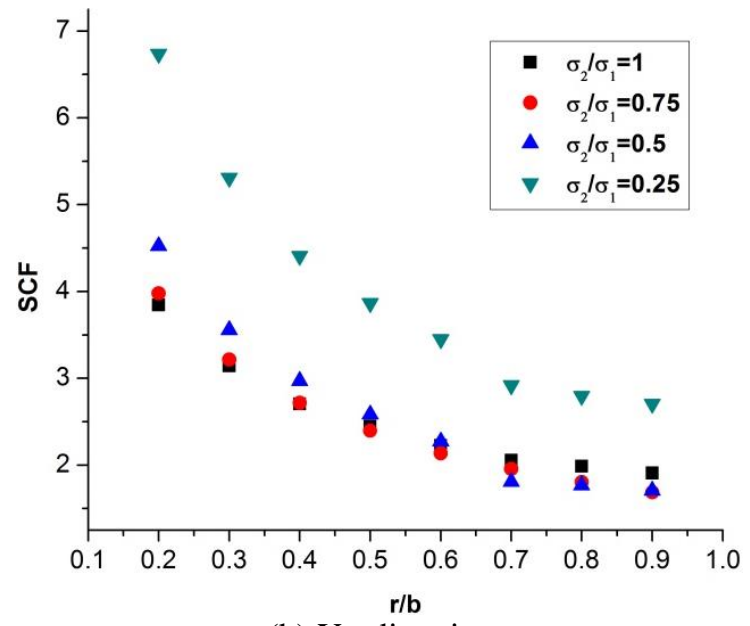

(b) Y - direction

Figure 7. Variation of SCF with loading ratio for $\mathrm{b} / \mathrm{a}=1$

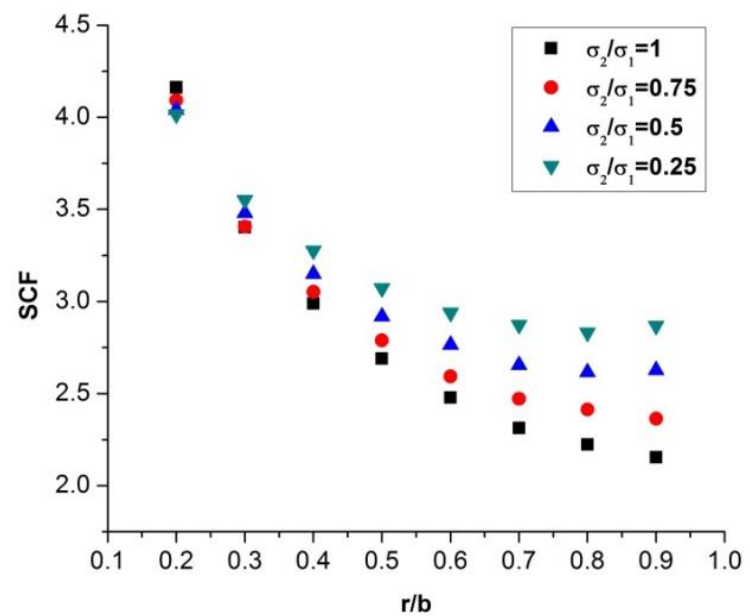

(a) $\mathrm{X}$ - direction

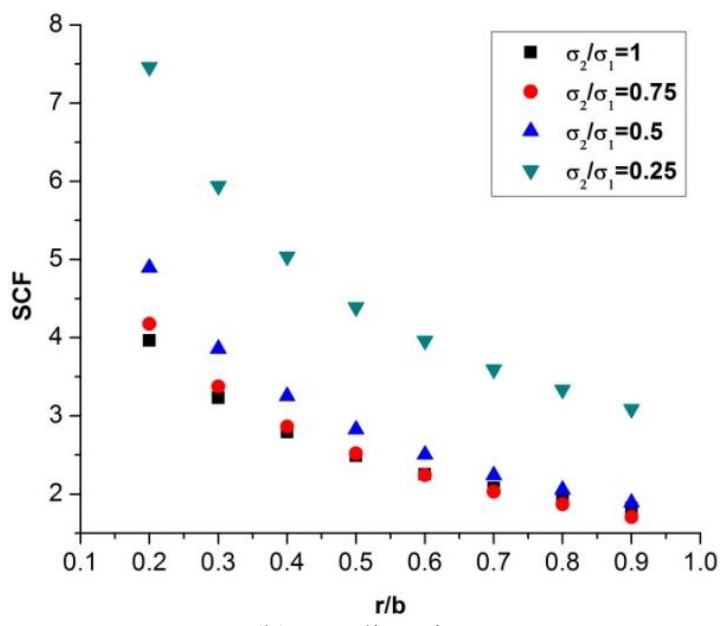

(b) Y - direction

Figure 8. Variation of SCF with loading ratio for $\mathrm{b} / \mathrm{a}=0.8$ 
International Journal of Mathematical, Engineering and Management Sciences

Vol. 4, No. 1, 66-76, 2019

https://dx.doi.org/10.33889/IJMEMS.2019.4.1-006

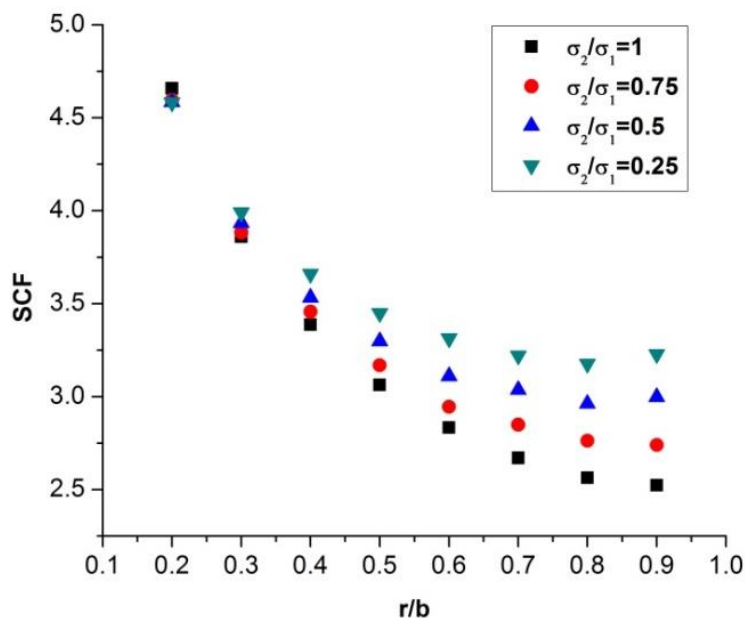

(a) X - direction

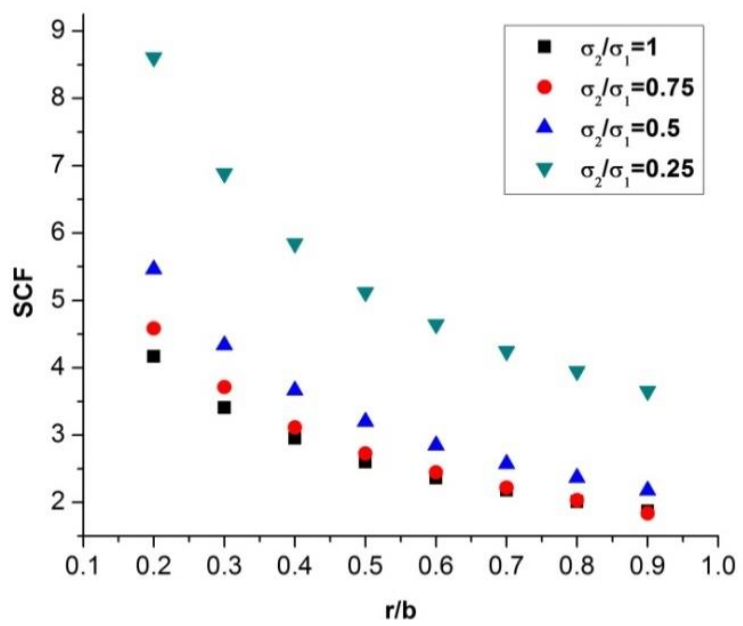

(b) Y - direction

Figure 9. Variation of SCF with loading ratio for $b / a=0.6$

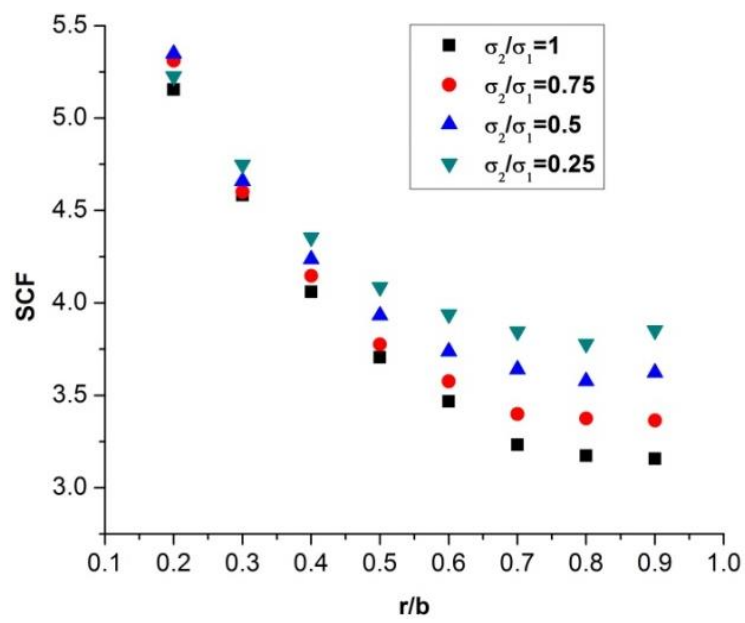

(a) $\mathrm{X}$ - direction

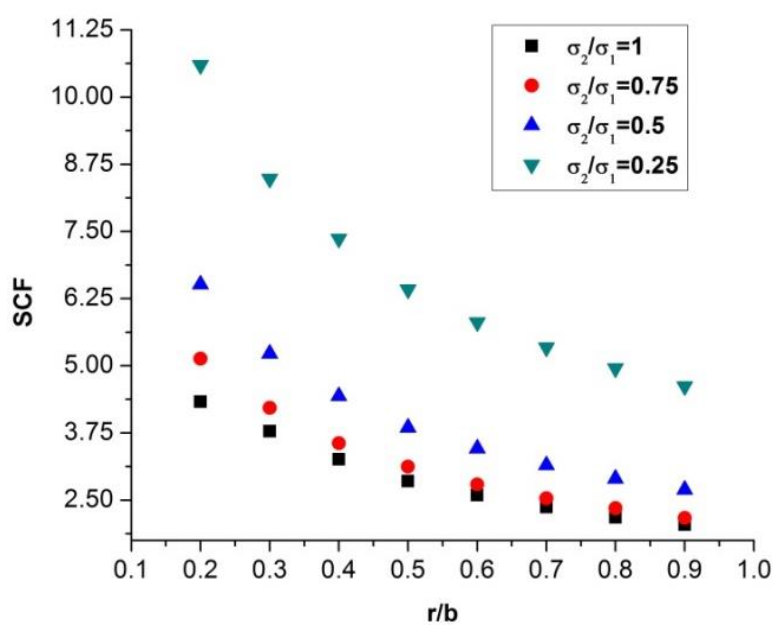

(b) Y - direction

Figure 10. Variation of SCF with loading ratio for $\mathrm{b} / \mathrm{a}=0.4$

Figure 7 - Figure 10 show the variation of SCF in X and $\mathrm{Y}$ directions with ' $\mathrm{r} / \mathrm{b}$ ' ratio under different stress states. All the curves exhibit reduction in SCF in both X and Y directions with increasing ' $\mathrm{r} / \mathrm{b}$ ' ratio under all stress states. It is observed that with an increase in loading ratio from 0.25 to 1 , the material near cut-out experienced smaller SCF irrespective of directions. This implies that the SCF are smaller when loading ratio is 1 due to the symmetry of the problem. Another important finding is that the ' $b / a$ ' ratio has profound effect on the SCF. The SCF in both $\mathrm{X}$ and $\mathrm{Y}$ directions showed significant increase with reduction in 'b/a' ratio. However, in $\mathrm{X}$ direction, the SCF was equal in all cases and loading ratios when the ' $\mathrm{r} / \mathrm{b}$ ' ratio in 0.2 . With 
International Journal of Mathematical, Engineering and Management Sciences

Vol. 4, No. 1, 66-76, 2019

https://dx.doi.org/10.33889/IJMEMS.2019.4.1-006

increasing ' $\mathrm{r} / \mathrm{b}$ ' ratio, the SCF differ significantly from each other. This implies that for small fillet radius the effect of loading ratio becomes less pronounced in the case of X-direction SCF. This does not hold good for Y-direction SCF. As far as Y - direction SCF is considered, under loading ratio 0.25 , the SCF is observed to be significantly higher in comparison with other loading ratios. Also, the Y-direction SCF showed insignificant dependence on loading ratio throughout the ' $\mathrm{r} / \mathrm{b}$ ' ratio range ' $\mathrm{b} / \mathrm{a}$ ' ratio between 1 and 0.6 .

\section{Conclusion}

The present paper aims at investigating the SCF induced in infinite plates containing rectangular cut-out with filleted corners. The plate was modeled and discretized using a commercially available finite element software ANSYS. The plate was subjected to uniaxial loading and values of SCF were obtained. The results were compared to analytical relations available in literature and good agreement was observed among them. Further, the plates were subjected to biaxial loadings and the effect of various geometrical parameters and loading scenarios was determined using FEM.

Under uniaxial loading, the SCF reduced significantly with increasing ' $r / b$ ' ratios. Cut-out with 'b/a' ratio equal to 1 exhibited lower SCF than with lower values. Highest values of SCF were obtained for ' $\mathrm{b} / \mathrm{a}$ ' value equal to 0.4. Under biaxial loading condition, the maximum SCF in Xdirection was observed to reduce with increasing ' $b / a$ ' ratio. Both $\mathrm{X}$ and $\mathrm{Y}$ direction SCF showed continuous reduction with increasing ' $r / b$ ' values. Variation in loading ratio $\left(\sigma_{2} / \sigma_{1}\right)$ from 0.25 to 1 induced smaller SCF in the plate.

\section{Conflict of Interest}

The author confirms that there is no conflict of interest to declare for this publication.

\section{Acknowledgement}

The author would like to express his sincere thanks to the referees for their valuable suggestions towards the improvement of the paper.

\section{References}

Dally, J. W., \& Riley, W. F. (1965). Experimental stress analysis. Mc-Graw Hill, New York.

Dave, J. M., \& Sharma, D. S. (2018). Stress field around rectangular hole in functionally graded plate. International Journal of Mechanical Sciences, 136, 360-370.

Garrell, M. G., Shih, A. J., Lara-Curzio, E., \& Scattergood, R. O. (2003). Finite-element analysis of stress concentration in ASTM D 638 tension specimens. Journal of Testing and Evaluation, 31(1), 52-57.

Khechai, A., Tati, A., Belarbi, M. O., \& Guettala, A. (2018). Numerical analysis of stress concentration in isotropic and laminated plates with inclined elliptical holes. Journal of the Institution of Engineers: Series $C, 1-12$.

Kumar, A., Agrawal, A., Ghadai, R., \& Kalita, K. (2016). Analysis of stress concentration in orthotropic laminates. Procedia Technology, 23, 156-162. 
International Journal of Mathematical, Engineering and Management Sciences

Vol. 4, No. 1, 66-76, 2019

https://dx.doi.org/10.33889/IJMEMS.2019.4.1-006

Lekhnitskii, S. G. (1968). Anisotropic plates (No. FTD-HT-23-608-67). Foreign Technology Div WrightPatterson Afb Oh.

Louhghalam, A., Igusa, T., Park, C., Choi, S., \& Kim, K. (2011). Analysis of stress concentrations in plates with rectangular openings by a combined conformal mapping-finite element approach. International Journal of Solids and Structures, 48(13), 1991-2004.

Muskhelishvili, N. I. (2013). Some basic problems of the mathematical theory of elasticity. Springer Science \& Business Media.

Rezaeepazhand, J. A. L. I. L., \& Jafari, M. (2010). Stress concentration in metallic plates with special shaped cutout. International Journal of Mechanical Sciences, 52(1), 96-102.

Savin, G. N. (1961). Stress concentration around holes (Vol. 1). Pergamon Press.

Sharma, D. S. (2011, July). Stress concentration around circular/elliptical/triangular cutouts in infinite composite plate. In Proceedings of the world congress on engineering (WCE 2011) (Vol. 3).

Sloan, C. S., Cowell, M. D., \& Lehnhoff, T. F. (1999). The effect of a large hole on the stress concentration factor of a satellite hole in a tension field. Journal of Pressure Vessel Technology, 121(3), 252-256.

Spotts, M. F. (1971). Design of machine elements. Pearson Education India.

Su, Z., Xie, C., \& Tang, Y. (2018). Stress distribution analysis and optimization for composite laminate containing hole of different shapes. Aerospace Science and Technology, 76, 466-470.

Ukadgaonker, V. G., \& Rao, D. K. N. (2000). A general solution for stress resultants and moments around holes in unsymmetric laminates. Composite Structures, 49(1), 27-39.

Wu, H. C., \& Mu, B. (2003). On stress concentrations for isotropic/orthotropic plates and cylinders with a circular hole. Composites Part B: Engineering, 34(2), 127-134.

Young, W. C., \& Budynas, R. G. (2002). Roark's formulas for stress and strain (Vol. 7). New York: McGraw-Hill. 